
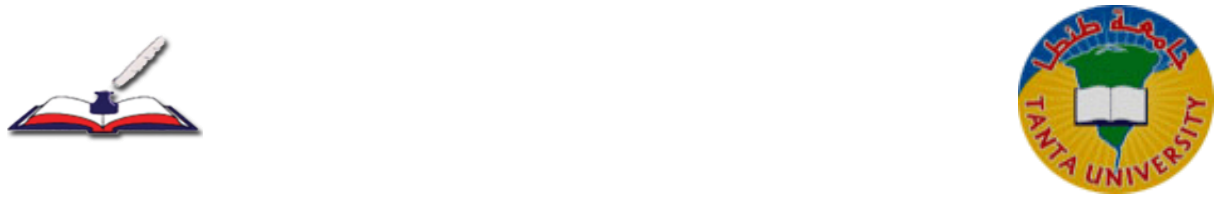

تحسين الثقة التنظيمية لاى العاملين بالمدارس الابتدائية

$$
\text { إعداد }
$$

أ/ مها محمد عيد سالم الغانم

ضمن منطلبات الحصول على درجة الماجستير

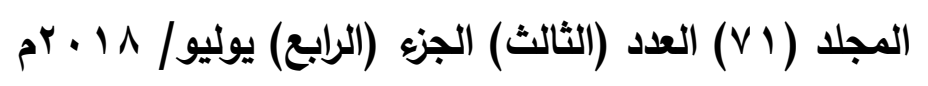


الثقة التظظيمية عنصر محوري في المدارس إذ أن غيابها يؤثر على فاعلية القيادة والأفراد بل والمدرسة ككل، فالمدرسة التي تسودها الثقة تعتبر بيئة عمل يحرص بـ الت الجميع على البقاء فيها. وفي هذا السياق فادارة المدرسة إذا استطاعت كسب ثقة

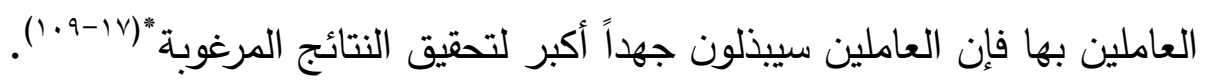
وغياب الثقة التظظيمية يؤدي إلى العديد من الآثار السلبية في بيئة العمل، والتي تتمثل في ضعف الأداء، وقلة الانتماء، وتفكك فرق العمل، وزيادة حدة الصراعات

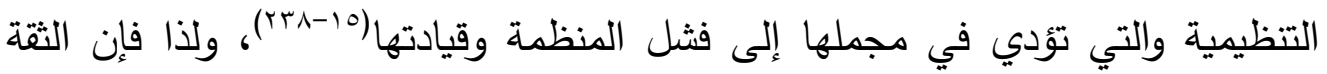
التنظيمية تُعد عاملاً حاسماً في مجال التعاون، والقيادة، وفاعلية المنظمة، والثقافة التظظيمية، وتساعد على تماسك أفراد المنظمة في جماعة متكاملة، وهى عامل رئيس في التفاعلات الإنسانية، وتعمل على زيادة فاعلية العلاقات، كما تساعد على بناء العلاقات الشخصية، وتشجع على الانفتاح وتخرج الطاقات الكامنة لدى أفراد المنظمة واستثمارها في العمل بصورة تطوعية. تُعد المرحلة الابتدائية مرحلة أساسية في النظام التعليمي سواء بالنسبة للمتعلمين أو بالنسبة للنظام التعليمي، فبالنسبة للمتعلم فإنها تشكل كثيراً من جوانب شخصيته بإكسابه المعارف والاتجاهات والتي تمثل الركائز الأساسية التي يعتمد عليها نموه في المراحل التالية، كما أنها تترك آثارها المتميزة في معالم شخصيته ومدى توافقه النفسي والاجتماعي، وبالنسبة للنظام التعليمي فهى حجر الزاوية في تطوير التعليم بكافة مراحله (·-10-1). مشكلة البحث: أشارت كل الدراسات السابقة التي رجعت إليها الباحثة إلى ما يلي: 1- - توافر الثقة التنظيمية في المدارس بمستوى جيد أمر ضروري لنجاح هذه المدارس في تحقيق أهدافها. 
r- - إن درجة الثقة التظيمية في المدارس الابتدائية تتراوح ما بين الضعيف والمتوسط، وهو ما يؤثر بالسلب على كفاءة هذه المدرسة. r- ضعف إلمام العاملين في المدارس الابتدائية بمتطلبات تطبيق الثقة التتظيمية في المدارس الابتذائية. وفي ضوء ما سبق، يمكن صياغة مشكلة البحث في الأسئلة الآتية: س ا ما الإطار الفكري للثقة التتظيمية كما تتاولته الأدبيات التربوية والإدارية؟ س ك كيف يمكن الاستفادة من مفهوم الثقة التنظيمية في المدارس الابتدائية؟ أهداف البحث:

يتمثل هدف الدراسة الرئيس في تعزيز مستوى الثقة التنظيمية لدى العاملين بالمدارس الابتدائية. ولتحقيق هذا الهدف انبثقت عنه عدة أهداف فرعية هى: 1- تعرف الإطار الفكري للثقة التنظيمية كما حددته الأدبيات التربوية والإدارية. r- بيان كيف يمكن الاستفادة من الثقة التنظيمية في تطوير العمل بالمدارس الابتدائية.

\section{أهمية البحث:}

تتبع أهمية الثقة التظظيمية للعاملين بالتعليم عامة، والتعليم الابتدائي على وجه الخصوص، إذ تتوقف فاعلية المدرسة وقدرتها على تحقيق أهدافها على غرس الثقة التظيمية لاى العاملين والتي تعزز لديهم الثعور بالانتماء، والولاء والأمن الوظيفي، والثقة في السياسات والإجراءات وعدالتها وهذا يسهم بشكل بارز في تعزيز المناخ الإيجابي في المدارس بصفة عامة والابتدائية خاصة، ويشجع على التعاون وتوطيد العلاقات الإيجابية بين العاملين فيها والمدراء.

$$
\text { منهج البحث: }
$$

تحقيقاً لأهداف الدراسة وإبرازاً لأهميتها ستستخدم المنهج الوصفي لكونه أكثر ملاعمة لطبيعة الدراسة والأنسب لتحقيق أهدافها، حيث يتم من خلاله جمع المعلومات وتنظيمها وتصنيفها وتحليلها وتفسيرها والمنهج الوصفي بأساليبه المختلفة لا يقتصر على جمع البيانات وتبويبها، وإنما يمضى إلى ما هو أبعد من ذلك، حيث يتضمن قدراً من التفسير لهذه البيانات(r-ءז'). 
1- الثقة التنظيمية (Organizational Trust):

الثقة التنظيمية عنصر مهم في معظم التبادلات الاجتماعية، ويتمثل في اعتماد

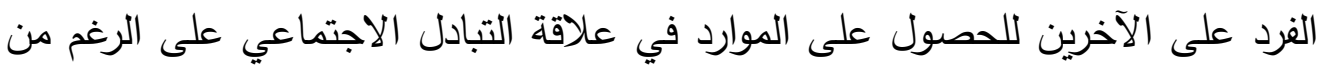

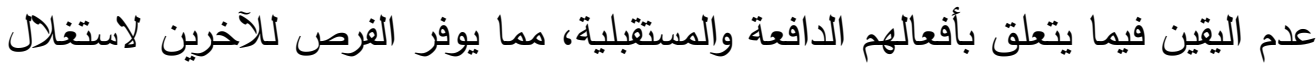

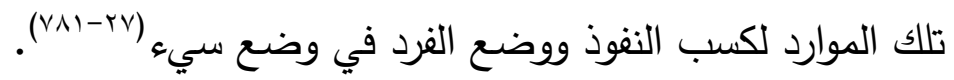

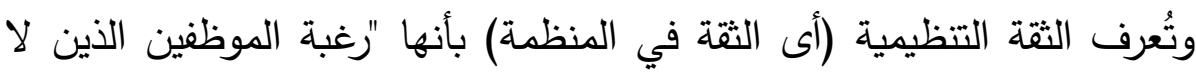

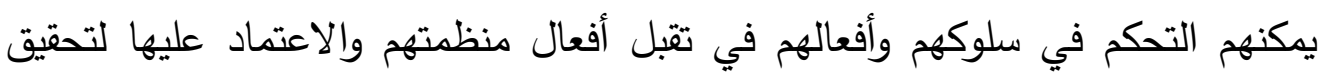

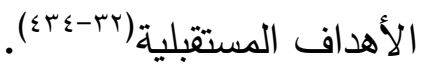

كما تعرف الثقة التنظيمية بأنها إيمان الموظفين بالقيادات التنظيمية، والاعتقاد بأن الإجراءات التنظيمية في نهاية المطاف ستفيد الموظفين والمنظمة على حد سواء، وهى مرتبطة بشكل كبير بالرضا الوظيفي، والالتزام التنظيمي، واني،

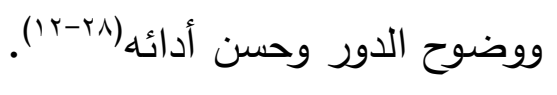

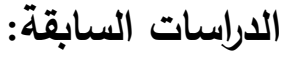

هناك الكثير من الدراسات السابقة من أهمها ما يلي:

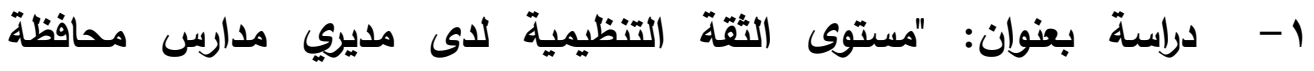

الأحمدي" (Y) (1)

هدفت الدراسة إلى تعرف الثقة التنظيمية لدى مديري مدارس محافظة الأحمدي

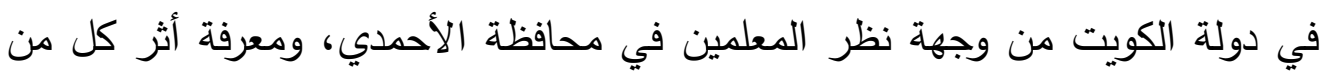

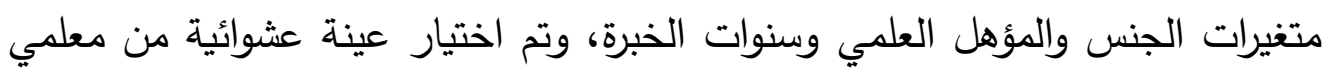

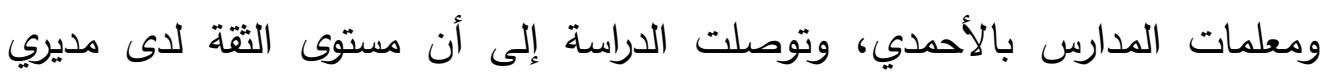

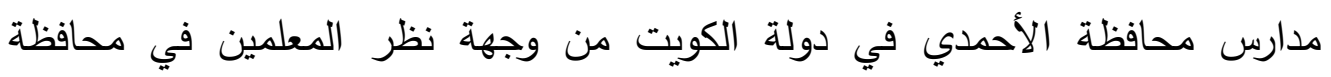
الأحمدي كان متوسطاً، إضافة إلى أن يثقون بثكل معتدل في مديرهم، وأظهرت النتائج

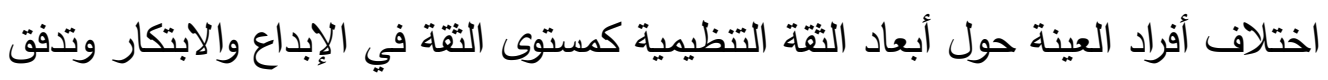
المعلومات والقيم التظظيمية السائدة حيث أن مستوى الثقة بهذه الأبعاد كان متوسطاً من الإندان الابكان وجهة نظر أفراد عينة الدراسة. 
r - التمكين النفسي وعلاقته بالثقة لاى المديرين المباشرين(r): هدفت هذه الدراسة إلى التعرف على العلاقة بين التمكين النفسي الثامل بجوانبها الأربعة (المعنى، والأثر، وحرية الإرادة، والكفاءة) والثقة القائمة على المعرفة والعاطفة لدى مديري البنوك نحو مديريهم المباشرين. واستخدمت الدراسة استبانة طبقت على • . F من مديري البنوك في أنقرة بتركيا. وتوصلت الدراسة إلى وجود علاقة كبيرة بين الثقة القائمة على المعرفة في المديرين المباشرين والتمكين النفسي العام على الرغم من أن الثقة القائمة على المعرفة ترتبط بجوانب المعنى والكفاءة، إلا أن الثقة القائمة على العاطفة مرتبطة بالتأثير فقط. r- - دراسة بيشيا أوغلو، وأوزير أوغرولو (beycioglu, Ugurlu) (rr) للوقوف على طبيعة العلاقة بين القيادة الموزعة وتصورات الثقة التتظيمية لدى المعلمين، هدفت الكثف عن الفروق في تصورات المعلمين حول سلوك القيادة الموزعة للمديرين كذلك الثقة التظظيمية في زملائهم، وتكون مجتمع الدراسة من (ب (Y) معلماً من المرحلة الابتدائية يعملون في مقاطعة سيفاس في غرب تركيا ولجمع البيانات طبق مقياس القيادة الموزعة في المدرسة كذلك مقياس الثقة التظظيمية. وأظهرت نتائج الدراسة أن المعلمين يشعرون بأن القيادة بمدارسهم موزعة ولدى المعلمين ثقة في مديريهم وزملائهم المعلمين. كما كثفت نتائج الدراسة أن ثقة المعلمين في زملائهم إيجابية متوسطة مع الثقة في المدير والقيادة الموزعة، كما أن الثقة في المدير لها ارتباط عال وموجب مع القيادة الموزعة. ثانيا: الإطار النظري للبحث: أولاً: ماهية الثقة التنظيمية:

هنالك اختلاف كبير بين الباحثين في تحديد ماهية مفهوم الثقة، ويرجع هذا الاختلاف في الأساس لاختلاف تخصصاتهم، ومن ثم ينظر كل باحث إلى المفهوم من وجهة نظر تخصصه العلمي، فعلماء النفس - على سبيل المثال - ينظرون إلى الثقة من منظور السمات الشخصية للفرد، على حين أن علماء الاجتماع ينظرون إلى الثقة على أنها إحدى السمات المميزة للمجتمع ونسيجه الاجتماعي. 


$$
\text { V.. }
$$

لقد ركز الباحثون في تفسير مفهوم الثقة على أنها درجة إيمان وتقبل الفرد للقرارات والسياسات التي تضعها إدارة المنظمة. والتي تقوم بتنفيذها وإدارتها بثكل عادل لجميع الأطراف، كما تعرف بأنها الإيمان العام والثقة بنوعية وقبول أشخاص معينين مثل زملاء العمل والرئيس المباشر أو مجموعات معينة مثل الإدارة العليا

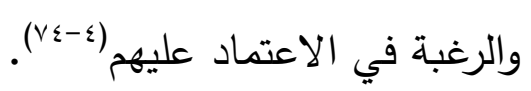
ويتم بناء الثقة التظيمية على أساس اعتقاد الطرف الأول بأن الطرف الآخر سوف يتصرف بفعالية (الاعتقادية)، كما تتضمن الثقة عنصر الاعتمادية بين طرفين أو أطراف الثقة، والتي تعني بأن أحد الأطراف سيتأثر بأداء الطرف الآخر (التأثير)، وتتضمن الثقة قدراً من المخاطرة، بسبب أن طرفي الثقة ليس لديهح معرفة أكيدة بكيفية

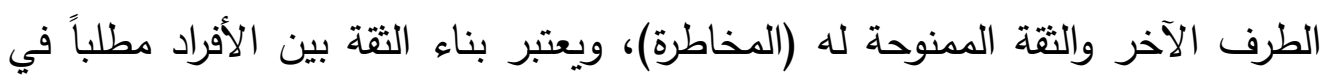
غاية الأهمية لتحقيق التكامل والتعاون بينهم، والوصول إلى غايتهم، خاصة في ظل تنوع خلفياتهم الثقافية وتوجهاتهم الثخصية، حتى وصل الأمر إلى أن الثقة التنظيمية تشكل عنصراً مهماً في تشكيل الثقافة التظيمية(-0). إن المنظمة يعمل بها الكثير من العاملين في مراكز مختلفة، ويقومون بأدوار مختلفة، وحتى تستطيع المنظمة أن تحسن من أدائها، وتحقق إنتاجية عالية ومتميزة، فلابد من تحقيق التكامل بين هذه الأطراف خاصـة فيما يتعلق بأدوارهم، ولن يتحقق هذا التكامل بين الأدوار إلا إذا تحققت الثقة، وأن يثق كل فرد في المنظمة في أن الفرد الآخر يقوم بدوره على أكل وجه، وأن العمل يسير في ضوء هذه الثقة المتبادلة بين العاملين. وهنا تتكون لدى الفرد الكثير من المعتقدات والقيم والاتجاهات والمشاعر الإيجابية التي تتكون تجاه المنظمة التي يعمل بها وينتمي إليها، وتجاه الزملاء والرؤساء، وهذه المعتقدات والقيم والاتجاهات والمشاعر مرتبطة دائماً بطبيعة السلوكيات

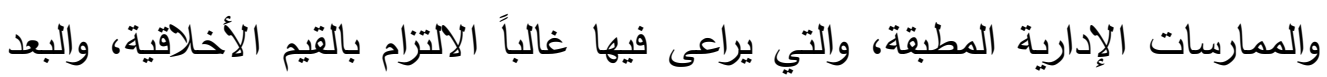
عن كل ما يشكل ضرراً بالمصالح المشتركة(·r-.9"). 
$v \cdot 1$

وتعبر الثقة التنظيمية عن التوقعات الإيجابية للفرد أو للجماعة أو الشركة

للسلوكيات أو الممارسات الأخلاقية التي تظهر في قرارات وتصرفات الطرف الآخر، المتمثل أيضاً في فرد أو جماعة أو شركة أخرى(الب-ه؛).

وتجسد الثقة التنظيمية الرغبة في التعاون مع الطرف الآخر، وذلك اعتماداً على

توقعات الطرف الأول الإيجابية تجاه الطرف الثاني، وذلك في ضوء التفاعلات الإيجابية الماضية (17-17.0). إن الثقافة التنظيمية تمثل حالة نفية تلضمن توافر النية لقبول الاعتماد على طرف آخر، وذلك نتيجة للتوقعات الإيجابية لدى الطرف الأول عن النوايا والسلوك المتوقع للطرف الثاني (rorrr).

وبناء على ذلك تصبح الثقة التنظيمية بمثابة "عقد نفسي ووجداني ومعنوي غير مكتوب بين طرفين، وعلى الرغم من أنه ليس مكتوباً إلا أنه يتم الالتزام به سلوكياً وإجرائياً، ويُعد هذا العقد المعيار الرئيس في الحكم على تصرفات الطرفين، وتقويم نوعية وطبيعة العلاقة بينهما، وينتج عنه ثقة متبادلة بين الواثق والموثوق به"(9 (-.؟؟ب). ثانياً: تطور الثقة التتظيمية:

حظى موضوع التثة التظظيمية في السنوات الأخيرة باهتمام الباحثين في الإدارة، ولاسيما في السلوك التنظيمي ونظريات التظيم، فقي الوقت الذي أصبحت فيه المنظمات لا تملك الخيار من منظمات معتمدة على الضبط والسيطرة إلى منظمات معتمدة على المعلومات، فإن الثقة تُعد المتطلب الأساس في ظل هذا التحول، من أجل مواجهة تحديات التكيف مع سرعة التغير في البيئة، فقد وجد أن مستوى الثقة التنظيمية يُعد عاملاً مهماً لتحديد ما إذا كان العاملون يسهلون أو يعرقلون عملية التغيير التتظيمي، وذلك في ضوء أن الأفراد يلزمون أنفسه بالأهداف التنظيمية التي يثقون بها، في حين أنهم لا يلقون بالاً لأهداف تتظيمية لا يثقون بها. وأصبحت العلاقات الإنسانية عاملاً رئيساً في جميع العمليات الإدارية، بل هى لهى لهاته في الحقيقة الأساس الأول لهذه العمليات، وذلك إيماناً بأن القيادة الحكيمة هى التي تعتمد على احترام الغرد، والعمل على رفع روحه المعنوية، ومنحه جميع حقوقه الإنسانية، وإشباع ما يتوقعه من عمله من حاجات مادية ونفسية، وقد كانت المدارس الإدارية القديمة تعد الإنسان أحد أدوات الإنتاج، بينما تتظر إليه النظريات الحديثة في مي مي 


\section{$V \cdot r$}

الإدارة على أنه محور العملية الإدارية كلها، وهو مركز الدائرة في التطوير التظظيمي

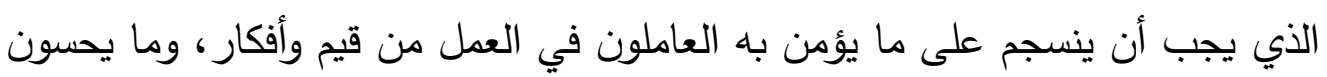

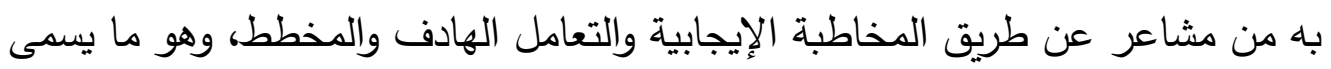
عادة بالعلاقات الإنسانية في العمل (r-1901).

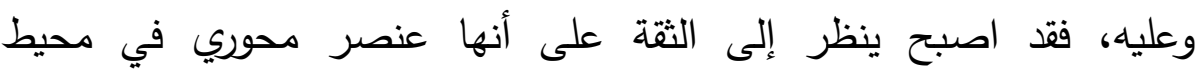

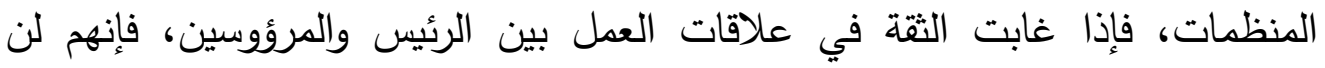

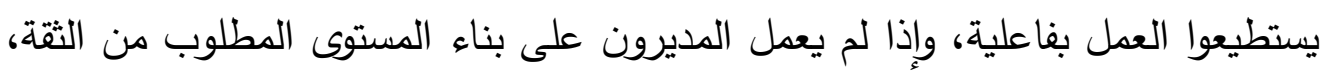

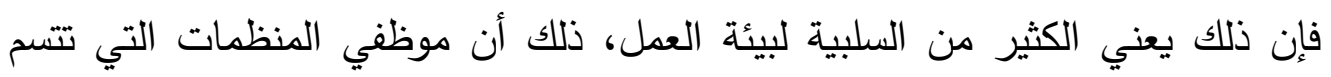

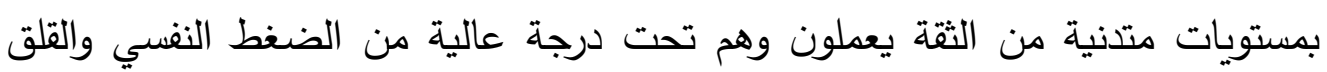

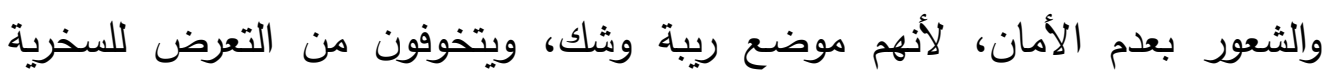

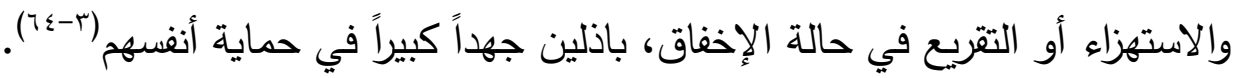
ثالثاً: القيادة ودورها في تعزيز الثقة: الثقة هى سمة رئيسية مرتبطة بالقادة، إذ أن الأمانة والاستقامة هي سمة حتمية

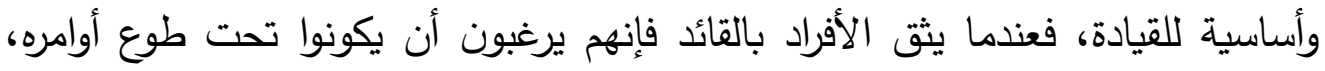

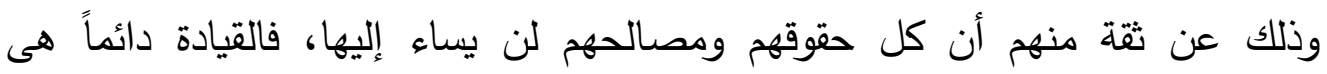

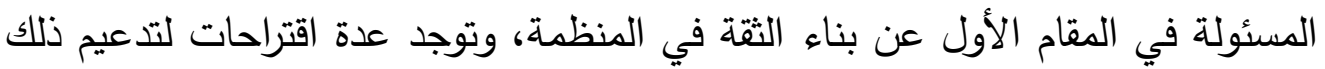

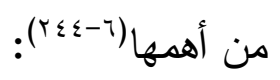
- ممارسة القيادة الإنسانية من خلال فهم مشاعرهم والحفاظ على أسرارهم.

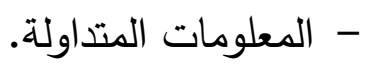
- يكون القائد نموذجاً للمصداقية في القول والعمل. - تطبيق السياسات التنظيمية والإجراءات والقواعد باستمرار .

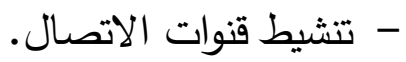

- إظهار الثقة والإيمان بالعاملين، والعمل على تقويض السلطة، والتأكيد على أهمية العمل

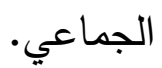
إن الثقة التنظيمية لا يمكن تحقيقها بكفاءة عالية، إلا عندما يصل المديرون إلى القناعة التامة بأن البعد الإنساني في التعامل بين المدرسين داخل المؤسسات 


\section{$v \cdot r$}

التعليمية لا يقل أهمية عن نشر ثقافة الثقة التنظيمية بين المدرسين، وتعتبر الإدارة من أهم العوامل المؤثرة في نجاح المؤسسات التعليمية، وحيث إن لكل مؤسسة أهدافها التي تسعى إلى تحقيقها، لذا، فلابد من تعزيز وتقوية الثقة التظيمية بين العاملين، وذلك من منطلق أنه كلما زادت درجة أو معدل الثقة بين العاملين يزيد العطاء والتفاني والتقدم والتضحية من أجل الرقي بمستوى الأداء إلى أن يصل إلى روح المنافسة، وبذل كل الإمكانات اللازمة من أجل سمعة المؤسسة والعاملين فيها (1) نوح-1)

ويعتبر البعد الإنساني من أهم العوامل التي تؤدي إلى زيادة الإنتاجية في العمل، والانتماء في المؤسسة التعليمية، لذا، فعلى مديري المدارس الثانوية أن يكونوا على مسافة واحدة من كل المدرسين، وأن يتعاملوا معهم بحب واحترام، حتى ينعكس هذا الأداء على المسيرة التعليمية، وأن تتوفر الثقة في التعامل فيما بينهم. رابعاً: الثقة التتظيمية في المدرسة الابتدائية: تُعد المدرسة الابتدائية إحدى المؤسسات التربوية التي أوجدها المجتمع لتربية أبنائه، من خلال بناء شخصياتهم من كافة جوانبها، وفقاً لقدراتهم واستعداداتهم ورغباتهم واتجاهاتهم وميولهم، وتحتل المدرسة الثانوية أهمية استثنائية نظراً للدور الذي تؤديه في تتمية الجيل الجديد، والعمل على تطويره وإعداده للحياة الأكاديمية أو العملية، وعليه فلابد أن تكون إدارتها على درجة عالية من الكفاءة والمقدرة في المجالات الإدارية والفنية للتمكن من مواجهة المشكلات المختلفة، ومعالجتها بأسلوب موضوعي يعتمد على التحليل والتفكير · وأن يتمتع مديرها بكفاءات وقدرات ومهارات تمكنه من أداء مهماته وأدواره المتعددة على الوجه الأكمل، بوصفه قائداً ومربياً وموجهاً ومرشداً، يعمل على توفير مناخ مدرسي إيجابي وفعال، تسوده الثقة في التفاعل والتعاون بين جميع

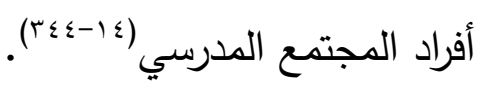
وفي ظل الممارسات الحيوية والمفاهيم الحديثة في علوم الإدارة، والتعامل مع العاملين، تبقى الجودة مطلباً منشوداً في بيئات العمل لتلك المنظمات التي تقدم خدمات، وعلى رأسها المدرسة الابتدائية، وبهذا يمكن أن نؤكد أن تفعيل التقة التتظيمية في المدارس يكون داعماً لتوافر عناصر الجودة ومعاييرها، وهو بالتالي قد يكون أحد أهم 


\section{$V \cdot \varepsilon$}

العوامل المؤثرة في رفع مستوى المناخ الصحي الوظيفي، كما أن توافر الثقة التظيمية في المدارس يخفف من المناخ المشحون في المدرسة، أو يمكن القول بأنه يقضي عليه، ومن ثم تصبح المدرسة بيئة خصبة لنمو مفاهيم الجودة وتطبيقها بشكل مرن، وعلى العكس، حيث تسود الخلافات بين أفراد المجتمع التعليمي، فإن المناخ المدرسي يصبح مشحوناً، مما يجعل من المدرسة بيئة طاردة للإبداع، وبدلاً من أن يركز مدير المدرسة في التخطيط والتحسين المستمر، فإنه يقضي معظم وقته في حل المشكلات، ومتابعة القضايا والخلافات، ومحاولة إيجاد الحلول لزرع الثقة بينه وبين العاملين معه، وبين

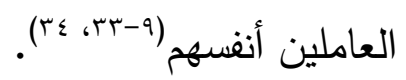
والمدرسة الابتدائية بوصفها نظاماً اجتماعياً معقداً يحتاج أطرافه إلى الثقة بعضهم ببعض، فالمعلم يعتمد على المدير في توفير البيئة المناسبة للتعليم، والمدير يعتمد على المعلم في تعليم التلاميذ ما يقرره المجتمع من مناهج وفقاً لقدراتهم وحاجاتهم، والمعلم يعتمد على الطالب في التفاعل الصفي، وأولياء الأمور يعتمدون على ملى المعلمين في تتمية دوافع التعلم لدى أبنائهج، والمعلم يعتمد على أولياء الأمور في تهيئة أبنائهم للاندماج في التعلم، وكل هذه العلاقات الاعتمادية تحتاج إلى الثقة كقاعدة للتعامل السليم فيما بينهم(ب-1099).

إن نشر مفهوم الثقة التظظيمية في المدارس الابتدائية، والعمل على بناء جسور الثقة بين جميع الأطراف في العملية التعليمية، خاصة ثقة المدير في المعلمين والطلبة وأولياء الأمور يؤدي إلى اتباع النمط القيادي والإداري، ويحدد ملامح المناخ التظظيمي، والرضا عن العمل، وارتفاع الروح المعنوية، وكلها عوامل تؤثر بشكل مباشر في

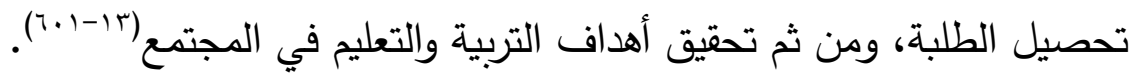
إن العامل المهم في بناء مناخ يدعم التعاون، يتمثل في بناء مناخ من الثقة بين الأفراد العاملين، لأن الثقة تسهم في تعزيز الفاعلية التنظيمية للمدارس، وقد يضعف عدم الثقة هذه الفاعلية، فالمديرون الذين لا يثقون في المعلمين لا يشاركونهم في السلطة والمسئولية، والمعلمون الذين لا يثقون في بعضهم لا يبذلون جهداً من أجل التعاون مع الآخرين، لذا يُعد التعاون والثقة عمليتين متبادلتين تعتمد إحداهما على تبني الأخرى،

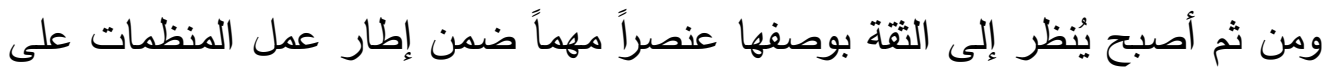




$$
\text { V.o }
$$

اختلاف أنواعها، ويتعذر على الأفراد والمنظمات العمل بفاعلية حال غيابها، فإذا لم عثم يتمكن المديرون من بناء المستوى المطلوب من الثقة، فقد يترتب على ذلك كثير من الآثار السلبية لبيئة المنظمة، ولهذا، يُعد بناء الثقة لدى العاملين مسألة ذات أهمية كبيرة

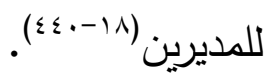

إن الثقة تحتل أهمية استثنائية في البيئة التربوية، إذ ينبغي أن تسود جميع التفاعلات اليومية التي تحدث بين العاملين في المؤسسات التربوية التي تهدف إلى بناء الإنسان بشكل متكامل في جميع جوانب شخصيته، ووفقاً للمواصفات والخصائص التي يريدها المجتمع لأبنائه، فالتعامل أو التفاعل الذي لا يتم بناء على الثقة لا يُعد صادقاً

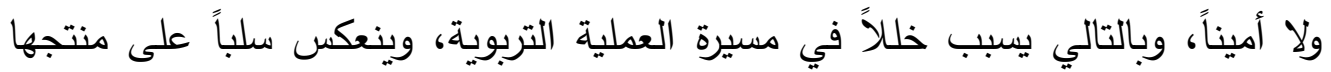
النهائي المتمثل في الطالب الذي ينتظره المجتمع للقيام بالمههات التي ستوكل إليه(اء(r) $r$ r $r \leq 0$

خامساً: أهمية الثقة التنظيمية وأهدافها:

حدد فيزوري Fizroy الكثير من جوانب أهمية الثقة التظيمية فيما يلي (بr): 1- الثقة التظيمية تجعل العمل في المنظمة يتسم بالتماسك والجودة العالية. r - تزيد الثقة التتظيمية من ولاء العاملين وانتمائهم للمنظمة. r- تشجع الثقة على الحوارات والنقاشات المفتوحة بين الزملاء في العمل، وتقلل من حدة الصراع التنظيمي. ع - تقلص كثيراً من معدلات غياب العاملين أو تأخرهم عن العمل. 0- - تحفز العاملين على الوصول إلى مستويات الإبداع والابتكار . تعتبر الثقة التتظيمية متطلباً أساسياً للتحول من الاعتماد على السيطرة والرقابة إلى الاعتماد على المعرفة والمعلومات من أجل مواكبة التطورات ومواجهة التحديات الجديدة، ولذا فهى تحتاج إلى قواعد لابد من مراعاتها لبناء مناخ من الثقة

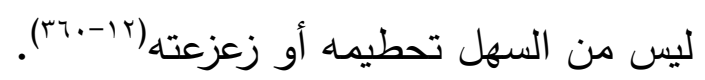
وتؤدي الثقة التظيمية- كأحد أنشطة المسئولية الاجتماعية للمنظمات- دوراً رئيساً في تعزيز مواقف الموظفين وسلوكياتهم، حيث تعد الثقة التنظيمية أمراً بالغ 
الأهمية للموظفين للإيمان بمؤسساتهم وقيمها وأهدافها، وفي نفس الوقت تمكن الموظفين

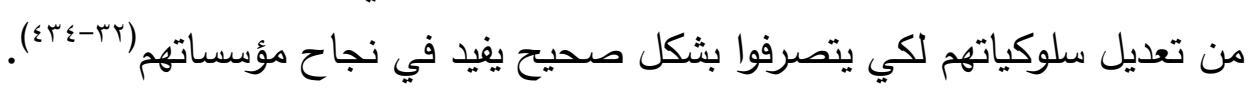
سادساً: أنواع الثقة التنظيمية: ويمكن تحديد نوعين من الثقة وهما:

Contractual Trust الثقة التعاقدية

والمقصود بها أن الاتفاق والتفاعل بين الأطراف يتضمن التعهد من أحد الأطراف، وتوقع الوفاء من الطرف الآخر، سواء كان ذلك الاتفاق حقيقياً أو تطور ضمنياً، وتم تطوير هذا النوع من الثقة من خلال التعاون بين الأفراد، والانسجام في السلوك والعلاقات، وعن طريق عقد السلوك الاجتماعي أو العقد النفسي للمعاملات اليومية الذي أشرنا إليه عند تحديد مفهوم الثقة.

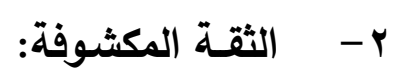

وهى التوقعات التي يحصلها الفرد أو الجماعة، إن عملية إظهار المشاعر والآراء والاتجاهات والقيم للآخرين لا تؤدي إلى الإضرار بالفرد أو الجماعة، بل العكس من ذلك، فإنها من الممكن أن تؤدي إلى زيادة الاحترام والتقدير •

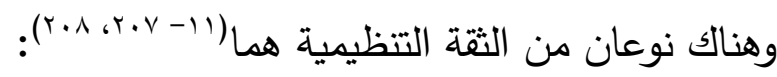

\section{Vertical Trust الثقة العمودية}

وتشير إلى ثقة المرؤوس في رئيسه، إذ عندما تعزز الثقة بين الرئيس

$$
\begin{aligned}
& \text { والمرؤوسين، يتمكن الرؤساء من إنجاز التغييرات المطلوبة. }
\end{aligned}
$$

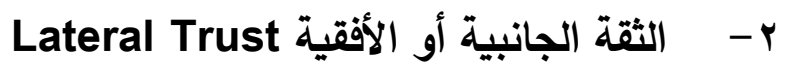

ويشير هذا النوع إلى الثقة بين الزملاء في العمل، وذلك نظراً لعلاقة

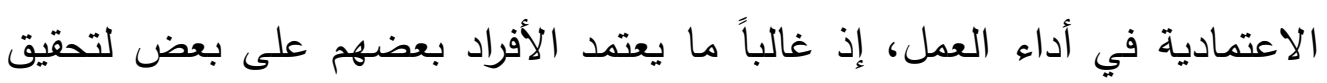
الأهداف الثخصية والتنظيمية. سابعاً: أبعاد ومكونات الثقة التنظيمية

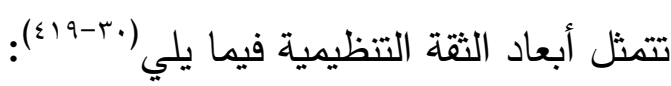




$$
V \cdot V
$$

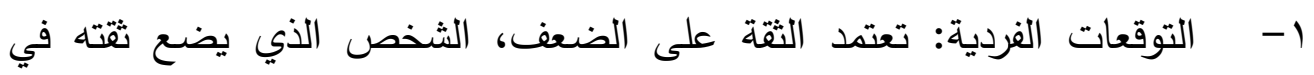

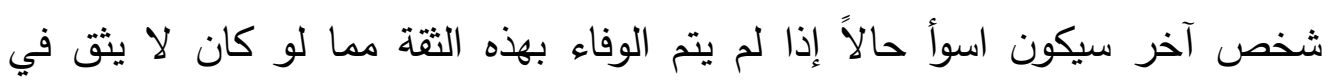

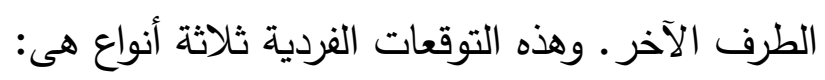

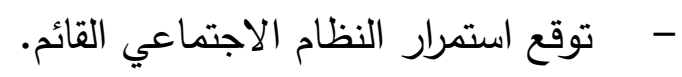

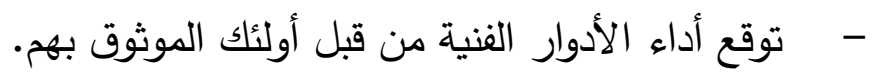

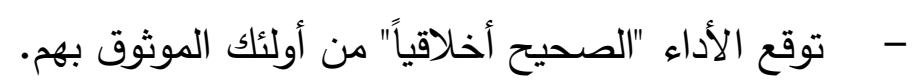

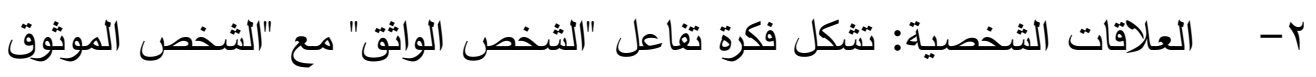

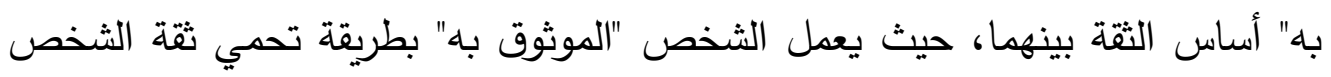

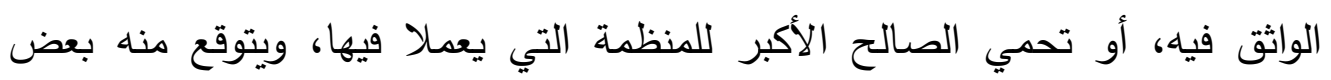
السلوكيات والنتائج التي تفي بهذه الثقة.

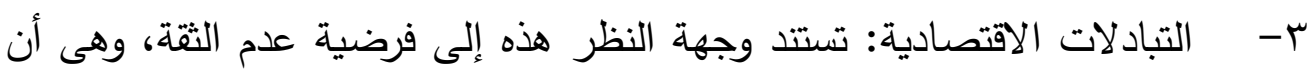

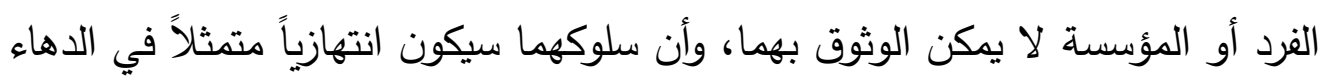
والسعي لتحقيق المصلحة الذاتية. ع - الهياكل الاجتماعية: الثقة ظاهرة اجتماعية وليست شخصية، ولأن تفاعلاتتا

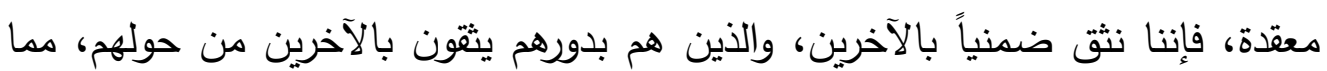

$$
\text { يؤدي إلى خلق "تتظيم اجتماعي للثقة". }
$$

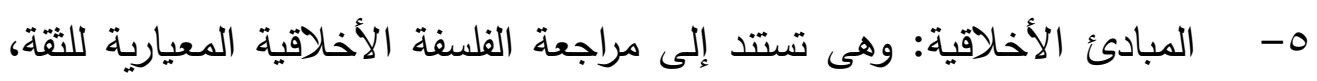

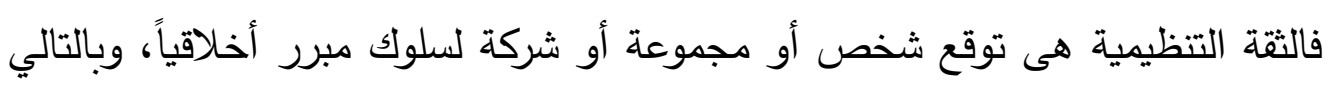
تتمثل الثقة في القرارات والإجراءات الصحيحة من الناحية الأخلاقية إلى المبادئ الأخلاقية.

وحدد بعض الباحثين أبعاد الثقة التنظيمية، فيما يلي (1-1):

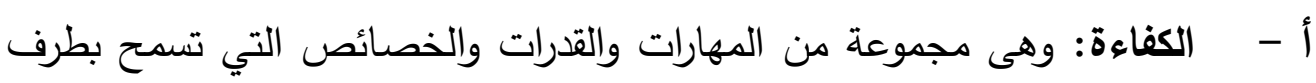

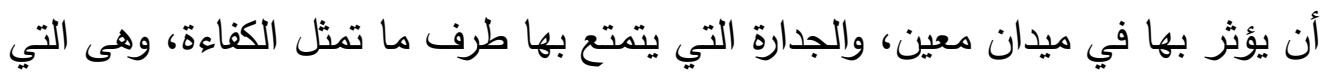

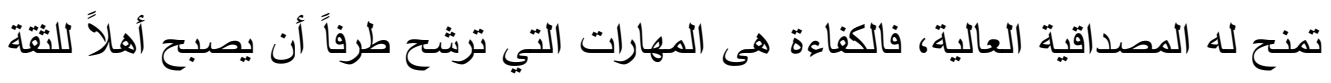

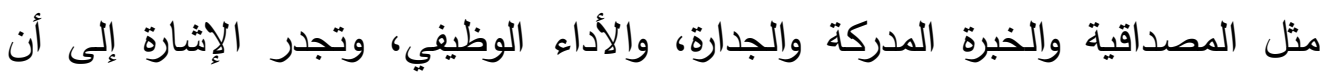




$$
v \cdot \Lambda
$$

الكفاءة مرتبطة في جانب من جوانبها بطبيعة الموقف، حيث يكون الشخص لله كفاءات في مجال معين، ولا يملك كفاءات في مجال آخر • ب- - الإيثار : وهو مدى اعتقاد طرف في طرف آخر مستعد أن يفعل لحسابه أشياء جيدة، مع كون الغايات بعيدة كلياً عن دوافع النفع والأنانية، والنزعة الخيرة تدرك بصفة إيجابية من طرف الموثوق نحو الموثوق به، فالمؤسسة التي تهتم بالعاملين بقدر أو أكثر من اهتمامها بالنتائج والعمليات، فإنها مؤسسة جديرة بالثقة، لأنها تبرز النزعة الخيرية تجاه العاملين والمدراء. ج- - النزاهـة: وهى الإدراكات التي كونها طرف نحو طرف آخر ، وهى المبادئ التي يتطلع إليها الأفراد في المنظمة، وتكون بمثابة المؤشر عن صدق وأمانة المؤسسة نحو المستخدمين والبيئة المحيطة بها، ولهذا ترتبط الثقة بخصائص الجماعة واتساقها مع القيم والمبادئ السائدة.

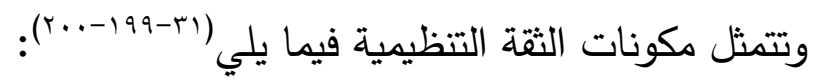

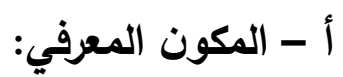
يثير المكون المعرفي للثقة التظيمية إلى اعتقاد تقييمي- وعادة ما يكون قدر معين من الخبرة والمعرفة- حول الثخص الآخر • وتستتد الثقة القائمة على المعرفة على التتبؤات والحسابات التقييمية، مثل احتمال السلوك المتبادل للطرف الآخر • وهذا التصور للثقة يعني أن أحد الطرفين يثق في الطرف الآخر لأن كلا الطرفين قد اتبعا نفس المبادئ الأخلاقية وعملوا بطريقة جديرة بالثقة في الماضي ويمكن توقع أن يفعلوا ذلك في المستقبل. وبالتالي، تنطوي الثقة القائمة على المعرفة على تقييم عقلاني يساعد الأطراف على عدم الثقة بشكل غير حكيم، فالثقة التنظيمية القائمة على المعرفة تعمل بشكل افضل فقط في الأمور قصيرة الأجل وغير العادية.

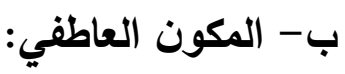
يرتبط المكون العاطفي للثقة التنظيمية بالجانب العاطفي أو التأثيري من وجود الثقة، فالثقة تُعد أولاً وقبل كل شئ تأثيراً، حيث يشير "التأثير" على شعور الفرد بالأمان العاطفي والجسدي، وغالباً ما يكون هذا الثكل من الثقة بديهياً وضمنياً وغالباً ما ينتج عن تفاعل على مدى فترة زمنية طويلة، والثقة القائمة على العاطفة أو التأثير 
استباقية، فهى تنطوي على توقع متبادل لسلوك عادل ونزيه، كما يتميز بالتوافق بين قيم ومصالح الأطراف المختلفة. وداخل المنظمات، هنالك حاجة إلى الثقة القائمة على التأثير لتحقيق التتمية التظيمية المستدامة مع التوجه على المدى الطويل. وبالتالي، لضمان الأداء المتميز المستدام، هناك حاجة على بيئة تتظيمية تشكل ثقافة العمل الداخلية، وتؤثر في السلوك الأخلاقي للموظفين، وتساهم في تطوير الثقة ليست فقط القائمة على المعرفة ولكن أيضاً الثقة القائمة على التأثير بين أعضاء المنظمة.

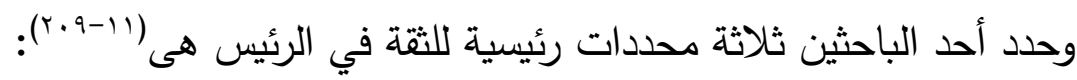

\section{1- النزعة لفعل الخير Benevolence}

وتعني اعتقاد وإيمان المرؤوس أن الرئيس يريد لله الخير، ولدييه نوايا حسنة تجاهه بعيداً عن الدوافع الأنانية أو المتمركزة حول الذات، كما تعني أن المرؤوس يعتقد أن رئيسه يهتم بمصالحه وأحواله، والرئيس النزاع للخير يقدم المساعدة لمرؤوسيه وإن لم يكن مطلوباً منه تقديمها، كما أنه لا يستخل مرؤوسيه حتى وإن سنحت الفرصة لذلك. Integrity r - ب الاستقامة أو التكامل

وتعني إدراك المرؤوس أن رئيسه يعتتق ويلتزم بمجموعة من المبادئ تعتبر مقبولة وإيجابية للمرؤوس، ويتصرف الرئيس بطريقة تتقق مع هذه القيم المرغوبة.

Ability القدرة

وتعني أن المرؤوس يدرك أن رئيسه يمتلك مجموعة من المهارات والكفاءات والمؤهلات في مجال عمله، تسمح بأن يكون لديه تأثير رسمي أو غير رسمي على الآخرين، وعلاقتها بسلوك المواطنة التنظيمية.

وتثير القدرة Ability إلى قدرة الرئيس على تحقيق آمال وتوقعات المرؤوسين في ضوء ما يمتلكه من مهارات وقدرات، وما بيده من سلطة تجعله قادراً على التحكم في الموارد التنظيمية(r-r-v).

أما المودة Benevolence فتشير إلى حجم الرعاية التي يوليها الرئيس

$$
\text { للمرؤوسين في إطار العلاقات الإنسانية التي تسود بنية العمل (عُ-.بآ). }
$$

أما النزاهة Integrity فتؤكد على التزام الرئيس في المنظمة بالقيم والمبادئ

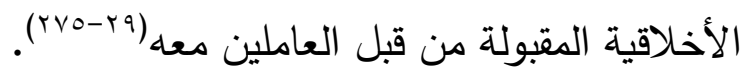


V).

وقد وضع تواى Toway نموذجاً للثقة يتكون من ثلاثة عناصر هى (ء):

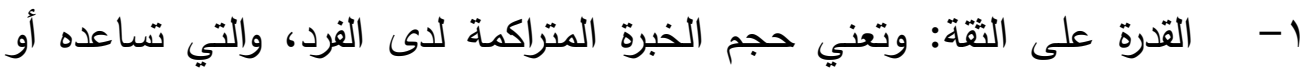
تدعمه على منح ثقته للآخرين. r- - القدرة على التعرف على الكفاءة أو القدرة: وتعني قدرة الفرد على إدراك قدراته الحقيقية وكذلك قدرات الآخرين ومهاراتهم لفهم مستويات الأداء المتميز ، وما تتطلبه هذه ونه المستويات العليا للأداء من مهارات وقدرات. r- القدان القدرة على التعرف على النوايا: وتعني قدرة الفرد في التعرف على نوايا الآخرين الذين يشاركونه العمل. ثامناً: العوامل المؤثرة في الثقة التنظيمية:

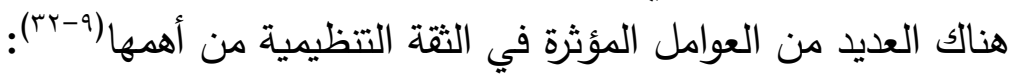

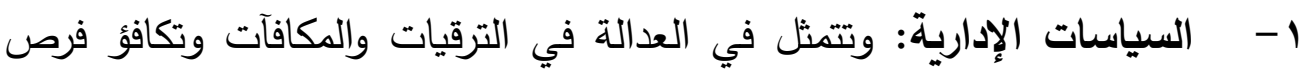
التدريس للعاملين، والثفافية في عرض الحقائق، والتعامل الجيد مع الأفراد العاملين.

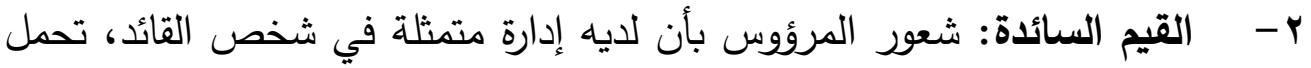
سمات التدين والالتزام الأخلاقي يرفع مستوى الثقة لديه، وأن ممارسات هذا القائد تتسم بالعدالة والموضوعية في القرارات، وأنه مجتهد في تحري الدقة.

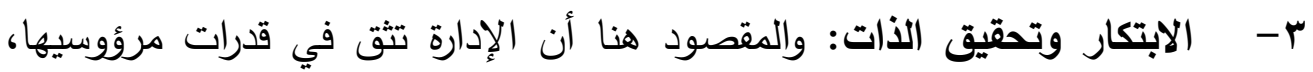
وتقدر جهودهم، وتفوقهم ببعض الصـلاحيات، وتشجعهم على الابتكار والتجديد في بيئة العمل، وتعمل على تتفيذ بعض مقترحاتهم وتقرها لديهم.

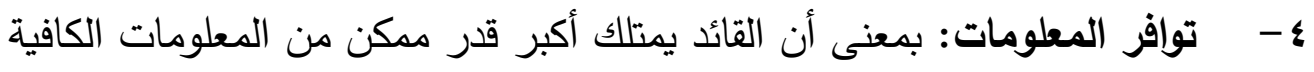
عن موظفيه وقدراتهم وتاريخهم وخبراتهم ووضعهم الاقتصادي والمعرفي والاجتماعي. ولزيادة الثقة بالإدارة والإدارة العليا، توجد بعض والثران الثروط التي تسهم في بناء الثقة التنظيمية هى (1/-. (1): ا - الأمن الوظيفي: إن ظروف العمل تقدم مستوى أعلى للأمن الوظيفي، فعندما يستشعر العاملون بالأمان والرضا الوظيفي، وأن المنظمة لا تفكر في تسريحهم من في العن العمل، فإن ذلك مدعاة لظهور الثقة التظظيمية بينهم. r - نوع المعاملة: إن عدالة الإجراءات والمعايير المتبعة في توزيع الأجور

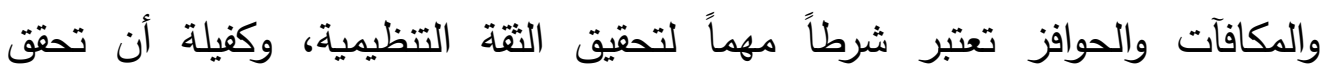
الإحساس العميق باحترام العامل للرؤساء والمسئولين. 
VII

r- - الاتصـال: من المؤكد أن زيادة حجم الاتصال بين العاملين بعضهم البعض، وبينهم وبين رؤسائهر، يُعد من أهم العوامل المؤثرة في بناء الثقة التظيمية.

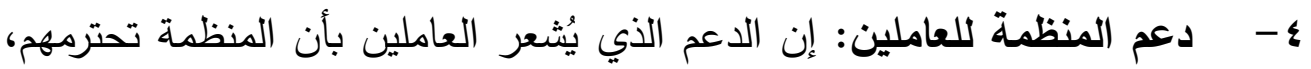

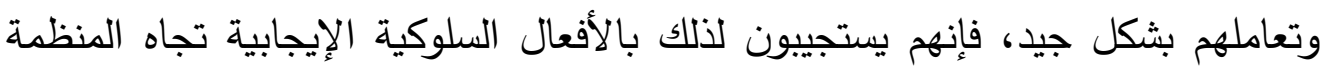
وتجاه المسئولين فيها. ثالثا: نتائج البحث: يمكن الخروج بمجموعة من النتائج من أهمها: ا - تُعد الثقة التنظيمية بمثابة عقد نفسي ومعنوي بين طرفين أو أكثر، يحتم الالتزام به سلوكياً وإجرائياً، ويُعد هذا العقد المعيار الرئيس في الحكم على تصرفات الأطراف المختلفة. r- تعمل الثقة التظظيمية على تخليص المنظمة من بعض الآفات الضارة مثل الاضطراب والقلق، الأمر الذي يساعد على شعور العاملين بالأمن والطمأنينة والراحة، بله والرغبة في بذل الجهد والعمل. r- تلعب الثقة التنظيمية دوراً كبيراً في تحسين العلاقات وتبادل الأفكار والمعلومات والآراء بين الأفراد، وكذلك تساعد على التكاتف من أجل إنجاز الأهداف المشتركة.

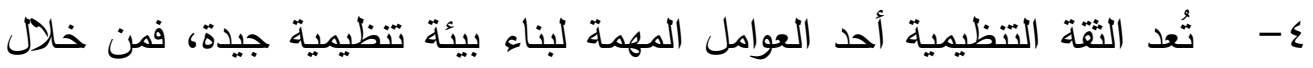
ترسيخ الثقة بين الأفراد بعضهم البعض، وبين العاملين والرؤساء، يكون ذلك كله أساساً لبناء بيئة محفزة ودافعة إلى العمل وداعمة لله، وعلى ذلك فقد أصبح ينظر إلى الثقة على أنها عنصر محوري داخل المنظمة، وإذا غابت الثقة من محيط المنظمة، فإنهم لن لن يستطيعوا العمل بفاعلية. ه- يجب أن يعمل مديرو المنظمات على بناء المستوى المطلوب من الثقة

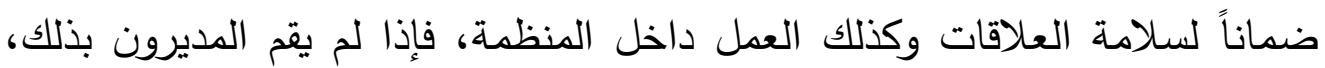
فإن ذلك من شأنه أن يجعل بيئة العمل تتصف بالكثير من السلبيات التي تؤثر على لعى كفاءة العمل، وأن يعمل العاملون داخل المنظمة تحت درجة عالية من الضغط النفسي والقلق والشعور بعدم الأمان.

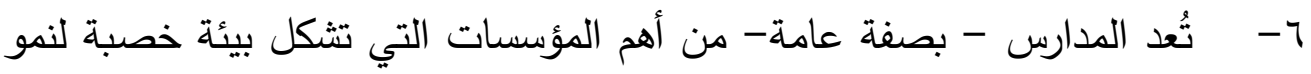
الكثير من المفاهيم الإنسانية ومن بينها الثقة التنظيمية. 


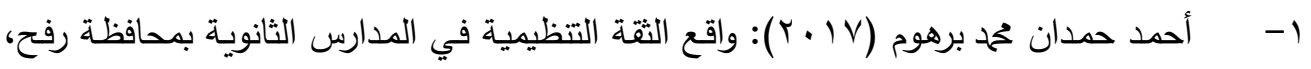

مجلة فلسطين للأبحاث والدراسات، مجV، عجا، عمادة الدراسات العليا والبحث العلمي، غزة.

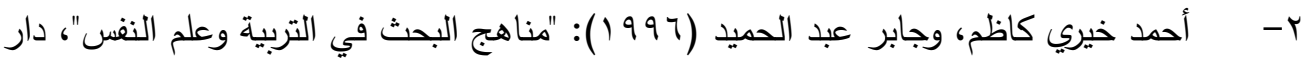

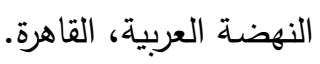

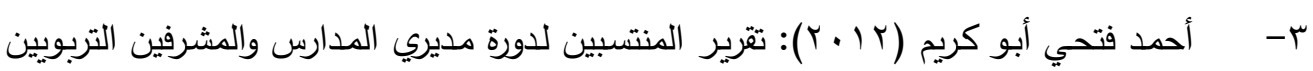

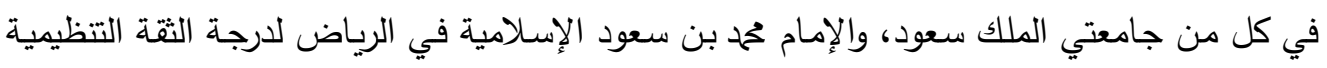

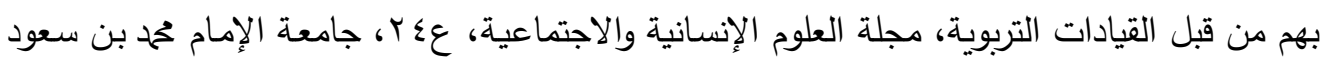
الإسلامية.

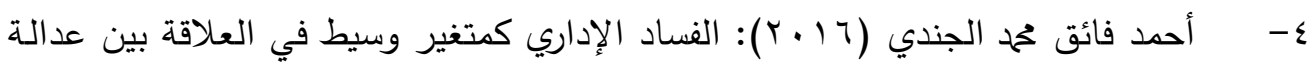
التوزيعات وتحسين الثقة التنظيمي: دراسة تطبيقية على العاملين بالوحدات المحلية بمحافظة

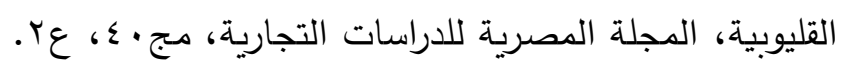

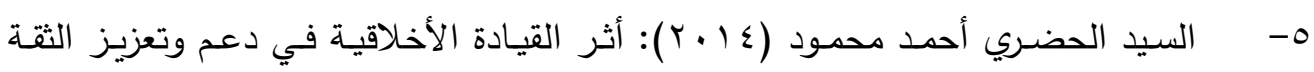

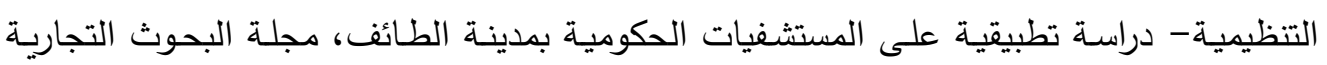

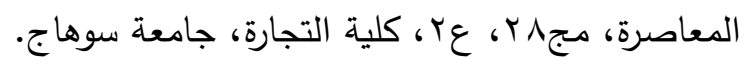

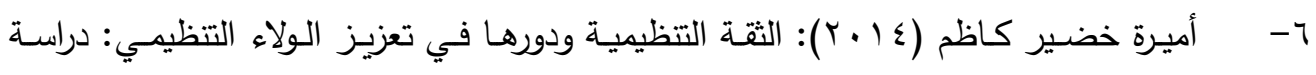
تطبيقية لعدد من العاملين في فروع مصرف الرافدين في محافظة النجف الأشرف، مجلة الغرى للعلوم الاقتصادية والإدارية، عابه، كلية الإدارة والاقتصاد، جامعة الكوفة.

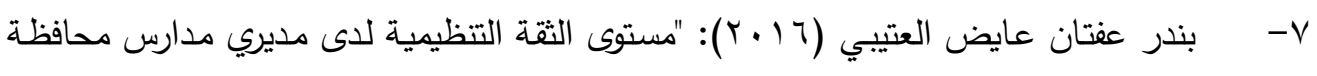
الأحمدي"، رسالة ماجستير غير منشورة، كلية العلوم التربوية، جامعة آل البيت، الأردن.

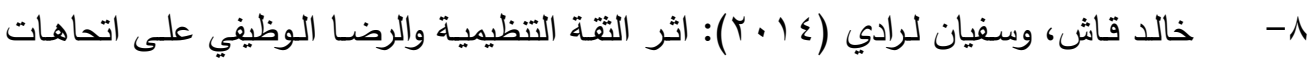
المستخدمين نحو التغيير، دراسة ميدانية في المضمون الجزائري، المؤتمر الدولي العلمي حول إدارة التغيير في عالم متغير ، مركز البحث وتطوير الموارد البشرية، رماح، الأردن.

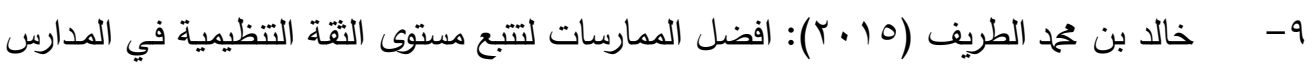

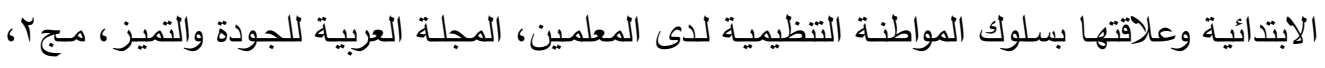

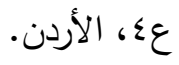

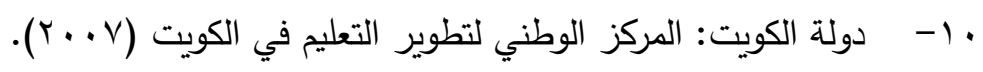

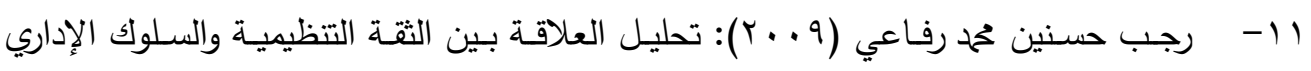

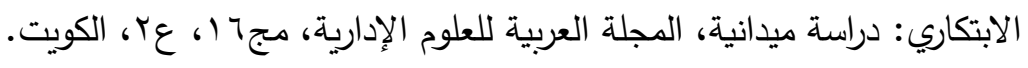




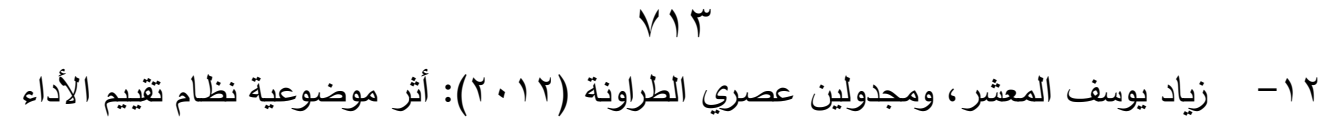

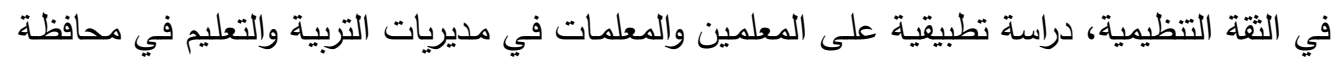

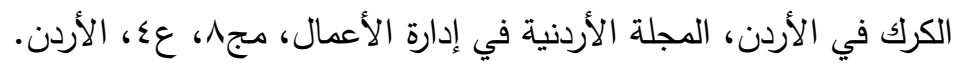

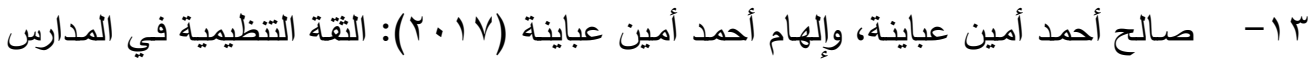

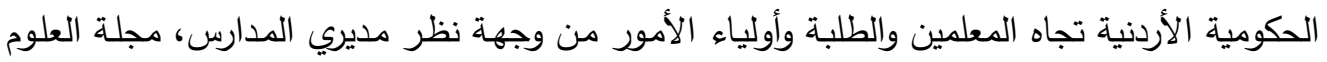

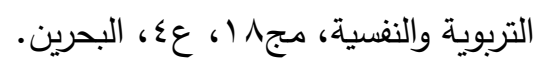

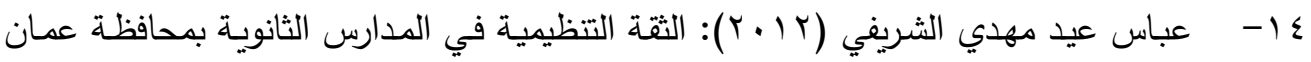
في ضوء بعض المتغيرات من وجهة نظر المعلمين، مرجع سابق.

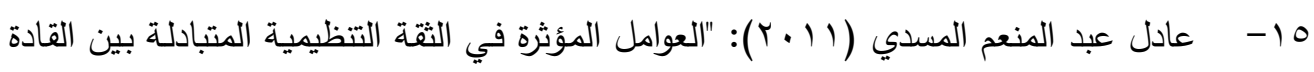

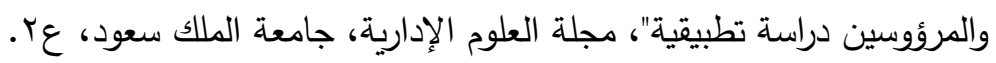

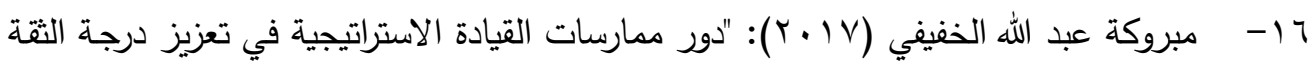

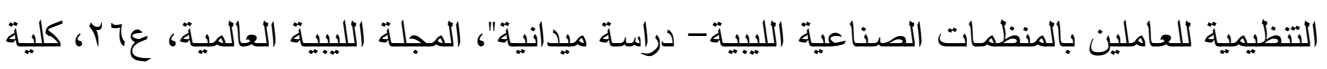
التربية بالمرج، جامعة بنغازي.

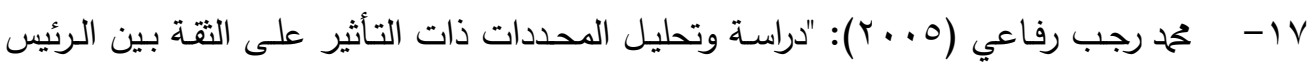

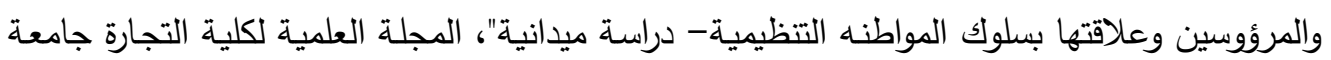
أسيوط، العدد الثاني.

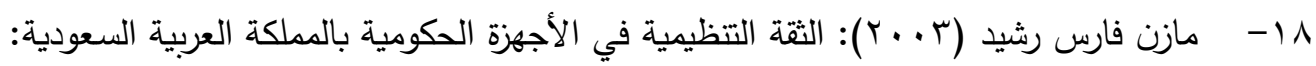

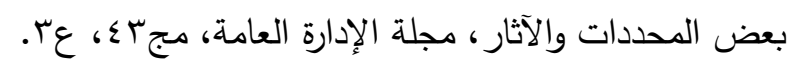

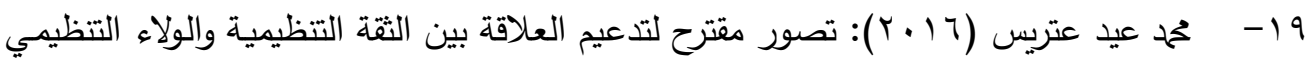

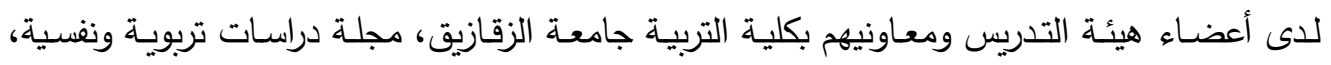
ع ع 9، كلية التربية، جامعة الزقازيق. 20- Altuntas, S. \& Baykal, U. (2010): Relationship Between Nurses Organizational Trust Levels and Their Organizational Citizenship Behaviors, Journal of Nursing Scholarship.

21- Adams, Barbard et al. (2008): Organizational Trust in the Canadian Forces, Defense Research and Development Canada, Toronto.

22- Azize Ergeneli Guler Saglam Arib Selin Metina (2007): Psychological Empowerment and its Relationship to Trust in Immediate Managers, Journal of Business Research. Volume 60, Issue: 1.

23- Beyeioglu, K. \& Ugurlu C. (2012): distributed Leadership and Organizational Trust: The Case of Elementary Schools, social and Behavioral Sciences. 46.

24- Burke, C. et al., (2007): Trust in Leadership: A Multi-level, Review and Integration, The Leadership Quarterly, Vol. 18. 
V) $\leq$

25- Canipe J.S. (2006): Relationship Among Trust, Organizational Commitment, Perceived Organizational Support and Turnover Intentions, Allint International University.

26- Fitzroy, Terry (2007): the Importance of Organizational Trust, www.articlesloase.com 11/10/2018.

27- James D. Werbel \& Paulo Lopes Henriques (2009): "Different Views of Trust and Relational Leadership: Supervisor and Subordinate Perspectives", Journal of Managerial Psychology, Vol. 24, Issue: 8.

28- Jill Pattison \& Theresa Kline (2015): "Facilitating a Just and Trusting Culture", International Journal of Health Care Quality Assurance, Vol. 28, Issue: 1 .

29- Lapierre, L. M. (2007): Supervisor Trust Worthiness and Superdinates, Willingness to Provide Extra Role Efforts, Journal of applied Social Psychology, Vol. 37, No. 2.

30- N.A.D. Connell \& R. Mannion (2006): "Conceptulisations of Trust in the Organizational Literature: Some Indicators from a Complementary Perspective", Journal of Health Ogranization and Management, Vol. 20, Issue: 5.

31- Raminta Pucetaite, Anna-Maija Lamsa \& Aurelija Novelskaite (2010): "Building Organizational Trust in a Low-trust Societal Context", Baltic Journal of Management", Vol. 5, Issue: 2.

32- Santhosh Manimegalai \& rupashree Baral (2018): "Examining the Mediating Role of Organizational Trust in the Relationship Between CSR Practices and Job Outcomes", Social Responsibility Journal, Vol. 14, Issue: 3.

33- Singh, H. \& Srivastava, K. (2009): International Trust and Organizational Citizenship Behavior, Psychological Studies, Vol. 54.

34- Toway (2004): Organizational Trust, www.ikhwan.net.19-2-2019.

35- Tzafrit, S.X. (2005): The Relationship Between Trust, HRMJ Practices and Firm Performance, The International Journal of Human Resource Management, Vol. 16, No. 9. 